\title{
MICROBIOTA CONTAMINANTE EM REPOLHO MINIMAMENTE PROCESSADO ${ }^{1}$
}

\author{
Elisabete FANTUZZI ${ }^{2}$, Rolf PUSCHMANN ${ }^{3}$, Maria Cristina Dantas VANETTI ${ }^{4, *}$
}

\section{RESUMO}

A microbiota contaminante de repolho minimamente processado foi avaliada durante as etapas de sanitização e estocagem sob atmosfera modificada passiva em embalagens com diferentes taxas de permeabilidade a $\mathrm{O}_{2}$ e $\mathrm{CO}_{2}$ e a $1^{\circ} \mathrm{C}, 5^{\circ} \mathrm{C}$ e $12^{\circ} \mathrm{C}$. A sanitização do repolho por 10min., à temperatura ambiente, em soluções sanitizantes de hipoclorito de sódio a $200 \mathrm{mgL}^{-1}$, de composto orgânico clorado a $200 \mathrm{mgL}^{-1}$ ou ácido acético a $1 \%$ reduziu em, no máximo, $1,8 \log _{10} \mathrm{UFCg}^{-1}$ a população de microrganismos aeróbios mesófilos. A concentração de $\mathrm{CO}_{2}$ no interior das embalagens variou significativamente $(\mathrm{P}<0,05)$ ao longo de 15 dias de estocagem do repolho minimamente processado mantido tanto a $1^{\circ} \mathrm{C}$ como a $5^{\circ} \mathrm{C}$. Nessas mesmas condições, não foi constatada variação na população de aeróbios e anaeróbios mesófilos e de psicrotróficos. Em avaliação subjetiva, o repolho minimamente processado apresentou-se em condições adequadas de consumo aos 20 dias de estocagem, a $1^{\circ} \mathrm{C}$ e $5^{\circ} \mathrm{C}$, nas embalagens de filmes de alta permeabilidade ao $\mathrm{O}_{2}$. Guando acondicionado em bandejas plásticas transparentes, seladas com filme de PVC termoencolhível, o produto apresentou, no vigésimo dia, a $5^{\circ} \mathrm{C}$, características sensoriais indesejáveis. O repolho minimamente processado mantido a $12^{\circ} \mathrm{C}$ apresentou sinais evidentes de deterioração após cinco dias, manifestados pelo aparecimento de manchas escuras, limosidade e odor desagradável, e teve um aumento de até $3 \log _{10} \mathrm{UFCg}^{-1}$ na população inicial de aeróbios e anaeróbios mesófilos e de psicrotróficos.

Palavras-chave: repolho; microbiota contaminante; minimamente processado; sanitização.

\section{SUMMARY}

MICROBIAL POPULATION IN MINIMALLY PROCESSED CABBAGE. The microbial populations associated with minimally processed cabbage after sanitation and storage at $1^{\circ} \mathrm{C}, 5^{\circ} \mathrm{C}$ and $12^{\circ} \mathrm{C}$ under modified atmosphere was analyzed. Sanitation of cabbage for ten minutes at room temperature in $200 \mathrm{mgL}^{-1}$ sodium hypochlorite and chlorinated organic compound or $1 \%$ acetic acid resulted in the reduction of up to $1.8 \log _{10} \mathrm{CFUg}^{-1}$ in the aerobic mesophilic bacteria population $(\mathrm{P}<0,05)$. At $1^{\circ} \mathrm{C}$ and $5^{\circ} \mathrm{C}$ significant $(\mathrm{P}>0.05)$ differences in concentrations of $\mathrm{CO}_{2}$ were found in the interior of the packages during fifteen days of storage. No variation was found in the mesophilic aerobic or anaerobic counts, and psycrotrophic microorganisms during storage at $1^{\circ} \mathrm{C}$ and $5^{\circ} \mathrm{C}$ for the three packaging materials used. The minimally processed cabbage was in good sensorial conditions for up to 20 days of storage at $1^{\circ} \mathrm{C}$ and $5^{\circ} \mathrm{C}$ in the packaging materials of high $\mathrm{O}_{2}$ permeability. The samples packed in transparent plastic trays sealed with thermal-shrinking PVC presented undesirable sensorial characteristics on the twentieth day of storage at $5^{\circ} \mathrm{C}$. After five days of storage at $12^{\circ} \mathrm{C}$ the fresh-cut cabbage presented evident signs of deterioration, as dark spots, slime and off odor. There was a $3 \log _{10} \mathrm{CFUg}^{-1}$ increase in the aerobic and anaerobic mesophiles and psycrotrophic populations in these samples.

Keywords: cabbage; microbial contaminants; minimally processed; fresh-cut.

\section{1 - INTRODUÇÃO}

O setor de hortaliças frescas minimamente processadas constitui um segmento da agroindústria em rápido crescimento, respondendo a maior demanda atual por produtos vegetais in natura, preparados convenientemente, para utilização em ambientes domésticos e institucionais [1]. Essa demanda por produtos vegetais minimamente processados tem levado a um aumento na quantidade e variedade de produtos disponíveis para o consumidor [13].

Além da qualidade sensorial, a qualidade microbiológica e a segurança das hortaliças frescas minimamente processadas precisam ser garantidas e são dependentes da microbiota presente na matéria-prima, da contaminação em cada etapa do processo e das condições de manutenção do produto, que podem permitir o crescimento microbiano. O manuseio impróprio e os equipamentos não sanitizados contribuem para o au-

\footnotetext{
Recebido para publicação em 22/06/2002. Aceito para publicação em 29/01/2004 (000868).

2. Faculdade de Nutrição - PUC, Campo Grande, MS.

3. Departamento de Biologia Vegetal-UFV, CEP: 36571-000, Viçosa, MG.

4. Departamento de Microbiologia-UFV, CEP: 36571-000, Viçosa, MG.

* A quem a correspondência deve ser enviada.
}

mento da população de microrganismos nas hortaliças, aumentando os riscos de patógenos e deterioradores nesses produtos [4]. O controle da microbiota contaminante é, portanto, fator determinante na manutenção da vida-de-prateleira e segurança do produto fresco.

O processamento mínimo compreende etapas de corte, lavagem, classificação, sanitização, centrifugação, embalagem e estocagem que interferem nos fatores físicos, químicos e biológicos responsáveis pela deterioração do produto [1,24]. Os cortes ou danos no tecido da planta promovem a liberação de nutrientes e enzimas intracelulares que favorecem a atividade enzimática e a proliferação de microrganismos no produto $[15,16,25]$. A atividade microbiana em produtos minimamente processados pode ser influenciada pelo metabolismo do tecido da planta, pela atmosfera modificada, pela permeabilidade do filme de embalagem e pela temperatura de estocagem.

O número e o tipo de microrganismos presentes em produtos minimamente processados são muito variados e a contagem de bactérias mesófilas nesses produtos após processamento varia de $10^{3}$ a $10^{9} \operatorname{UFCg}^{-1}[16,25]$. Para ZAGORY [25], apesar da existência de uma ampla e variada literatura sobre a dinâmica de população microbiana em produtos minimamente processados, os resul- 
tados são muitas vezes contraditórios, gerados sob diferentes condições experimentais e avaliados de acordo com diferentes critérios, além de refletir as condições e meios de cultura usados nas análises microbiológicas. Esse autor acrescentou ainda que a correlação entre o desenvolvimento de um número elevado de microrganismos e o fim da vida-útil do produto é questionável em razão de dados na literatura disponivel.

O tempo de vida-útil difere entre os tipos de produtos minimamente processados, mas varia entre 7 a 20 dias, quando mantidos nas temperaturas recomendadas [23]. A extensão desse período de vida-útil é uma das metas da pesquisa pós-colheita e, uma das formas de ser alcançada é otimizando as condições ambientais para diminuir a respiração do vegetal e o crescimento microbiano [21]. A temperatura é o principal fator que controla as atividades respiratórias, metabólicas e enzimáticas, a transpiração e o crescimento microbiano e, em produtos minimamente processados, o controle apropriado da temperatura pode inativar ou retardar essas transformações indesejáveis.

A embalagem sob vácuo ou atmosfera modificada é uma tecnologia que vem se expandindo como meio de conservação dos alimentos em resposta à demanda de produtos menos processados [13] e constitui barreira ao movimento do vapor d'água, podendo ajudar na manutenção da umidade relativa alta e do turgor dos produtos, além de impedir a contaminação e proteger o produto de abrasões superficiais. A atmosfera modificada promove também a redução da respiração do produto e as taxas de processos metabólicos, resultando em uma retenção do estado fisiológico e inibição do crescimento de microrganismos deterioradores [12, 13]. Os filmes plásticos influenciam as taxas de resfriamento e aquecimento do alimento e devem ser considerados na seleção de procedimentos apropriados ao estabelecimento da temperatura de estocagem adequada ao produto embalado.

Considerada a importância crescente de produtos frescos prontos para consumo no cenário nacional e internacional, o presente trabalho objetivou avaliar a microbiota bacteriana do repolho minimamente processado após etapa de sanitização e durante estocagem sob refrigeração de 1 e $5^{\circ} \mathrm{C}$ e sob abuso de temperatura, a $12^{\circ} \mathrm{C}$.

\section{2 - MATERIAL E MÉTODOS}

Utilizou-se plantas de repolho (Brassica oleracea var. capitata), completamente formados e desenvolvidos, que apresentavam cabeça compacta e folhas bem imbricadas. Os repolhos recém-colhidos foram mantidos em câmara fria, a $4^{\circ} \mathrm{C}$, por um dia, até o seu processamento.

O processamento mínimo consistiu das etapas de seleção, pré-lavagem, sanitização, corte, centrifugação e empacotamento. Na seleção, rejeitaram-se as unidades aparentemente danificadas. As folhas externas verdes foram removidas e procedeu-se a pré-lavagem, em água de torneira. As amostras foram separadas, aleatoriamente, para serem submetidas à sanitização. Foram utilizados três sanitizantes, consistindo de solução de hipoclorito de sódio a $200 \mathrm{mg} \mathrm{L}^{-1}$, solução comercial à base de composto orgânico clorado para verduras e frutas (Sumaveg ${ }^{\circledR}$ - Diversey Lever) na concentração de $0,66 \%$, que corresponde a, aproximadamente $200 \mathrm{mgL}^{-1}$ de cloro livre, e solução de ácido acético (Merck) a 1\%. Amostras de repolho imersas apenas em água serviram como controle da efetividade do processo. A hortaliça foi submersa nas soluções sanitizantes por um período de 10 minutos. $\mathrm{O} \mathrm{pH}$ das soluções sanitizantes foi determinado em potenciômetro Digimed (D-20).

O efeito do tipo de embalagem plástica sobre a conservação do repolho minimamente processado foi avaliado utilizando-se embalagens de poliolefina multicamada (PD900 e PD961 EZ da Cryovac ${ }^{\circledR}$ ) e em bandeja transparente, marca Galvano Tek IP2P, selada com filme de PVC termoencolhível. Segundo informações do fabricante, o filme plástico da embalagem PD900 é de baixa permeabilidade ao oxigênio, com a taxa de transmissão de gases de $3.000 \mathrm{cc} / \mathrm{m}^{2} / 24 \mathrm{~h}$ para $\mathrm{O}_{2}$ e de $9.800 \mathrm{cc} / \mathrm{m}^{2} / 24 \mathrm{~h}$ para $\mathrm{CO}_{2}$. A embalagem PD961 EZ, considerada de alta permeabilidade ao oxigênio, apresenta taxas médias de transmissão de $\mathrm{O}_{2}$ e $\mathrm{CO}_{2}$ de $7.000 \mathrm{cc} / \mathrm{m}^{2} / 24 \mathrm{~h}$ e $21.000 \mathrm{cc} / \mathrm{m}^{2} / 24 \mathrm{~h}$, respectivamente.

Em cada embalagem, foi colocado previamente um septo de silicone para coleta de volumes de $1,0 \mathrm{~mL}$ de gás do espaço livre, utilizando-se seringas descartáveis de $1,0 \mathrm{~mL}$. A concentração de $\mathrm{CO}_{2}$ foi determinada em cromatógrafo a gás, modelo GC 14B (Shimadzu, Japão) equipado com detector de condutividade térmica e com coluna empacotada com PorapaK-Q. A corrente utilizada foi de $85 \mathrm{~mA}$ e as temperaturas da coluna, do injetor e do detector foram, respectivamente, $60^{\circ} \mathrm{C}$, $100^{\circ} \mathrm{C}$ e $140^{\circ} \mathrm{C}$. A quantificação foi feita pela comparação das áreas dos picos das amostras com os obtidos após a aplicação de uma alíquota de 1,0mL de um padrão de 480ppm de $\mathrm{CO}_{2}$ (AGA Gases). Para a análise de $\mathrm{O}_{2}$ dentro das embalagens, coletaram-se, em triplicatas, alíquotas de 5,0mL do gás presente no espaço atmosférico das embalagens com seringas de 5,0mL. A quantificação do $\mathrm{O}_{2}$ foi feita em aparelho Mocon (Oxygen Headspace Analyzer - HS 750 Auto Ranging - EUA).

A microbiota contaminante do repolho minimamente processado foi avaliada pela contagem padrão de aeróbios e anaeróbios mesófilos [22] e psicrotróficos [6]. As análises foram efetuadas em porções de $25 \mathrm{~g}$ do material vegetal, pesado assepticamente e homogeneizado com $225 \mathrm{~mL}$ de água peptonada $0,1 \%$ (Merck), acrescida de $0,5 \%$ de Tween $^{\circledR} 80$. A seguir, foram feitas diluições decimais apropriadas, para se obterem contagens em placas entre 25 e 250 unidades formadoras de colônias.

$\mathrm{O}$ pH das amostras foi determinado em potenciômetro Digimed (DM 20), utilizando-se o método descrito por HAO et al. [11], modificando-se a quantidade da amostra de repolho para $50 \mathrm{~g}$, em $150 \mathrm{~mL}$ de água deionizada em sistema Milli- ${ }^{\circledR}$ (Millipore). 
O experimento para teste do sanitizante foi realizado segundo o delineamento inteiramente casualizado com três produtos (Sumaveg ${ }^{\circledR}$, hipoclorito de sódio e ácido acético) mais um tratamento controle, cada um com duas repetições. O teste de Tukey $(\alpha=5 \%)$ foi utilizado para comparação de médias dos logaritmos do número de unidades formadoras de colônia por grama $\left(\log \mathrm{UFC}^{-1}\right)$. Para estudo do efeito de tipo de embalagem, tempo e temperatura de estocagem, o experimento foi conduzido segundo o delineamento em parcelas subsubdivididas, com três tipos de embalagens na parcela, duas temperaturas $\left(1^{\circ} \mathrm{C}\right.$ e $\left.5^{\circ} \mathrm{C}\right)$ na subparcela, e três tempos $(5,10$ e 15 dias) de estocagem na subsubparcela, com três repetições. As amostras deterioradas não foram submetidas às análises microbiológicas nem incluídas na análise de variância (ANOVA).

\section{3 - RESULTADOS E DISCUSSÃO}

A imersão do repolho nas soluções sanitizantes avaliadas resultou em diminuição significativa de até $1,8 \log _{10} \mathrm{UFCg}^{-1}$ de bactérias aeróbias mesófilas em relação ao controle, lavado com água. No entanto, não houve diferença $(\mathrm{P}>0,05)$ na redução dessa microbiota contaminante entre as amostras de repolho tratadas com solução de $200 \mathrm{mgL}^{-1}$ de hipoclorito de sódio, 0,66\% de Sumaveg $^{\oplus}$ ou $1 \%$ de ácido acético.

$\mathrm{O}$ pH das soluções sanitizantes de cloro variou pouco, antes e após a sanitização. $\mathrm{O}$ pH da solução de Sumaveg ${ }^{\circledR}$ estava dentro dos limites de 7,5 a 8,5 , conforme informação do fabricante, enquanto o $\mathrm{pH}$ da solução de hipoclorito de sódio manteve-se em torno de $11 \mathrm{e}$, nesse valor, ocorre menor efetividade germicida do cloro.

Nos experimentos, as cabeças de repolho submetidas à sanitização não passaram pelo processo de enxágüe, conforme fluxograma seguido por outros experimentos de processamento mínimo [5, 8, 17, 18]. Embora o enxágüe seja uma etapa freqüentemente adotada após a sanitização de produtos minimamente processados $[3,7,9,19]$, os dados disponiveis na literatura sobre a necessidade dessa etapa não são conclusivos. Em alface minimamente processada, a população de psicrotróficos foi similar no produto submetido ou não ao enxágüe, o que não esclarece sobre os possiveis efeitos antimicrobianos exercidos pelo cloro residual [10].

Embora o pH da solução de ácido acético fosse de 2,7 , o tratamento de sanitização não causou danos aparentes na textura da hortaliça. A perda de textura de alface minimamente processada e tratada com $1 \%$ de ácido acético foi registrada por ZHANG \& FARBER [26].

\section{1 - Aparência do repolho minimamente proces- sado durante conservação}

O repolho minimamente processado, acondicionado nas embalagens PD900 e PD961 EZ, e mantido a $1^{\circ} \mathrm{C}$ e $5^{\circ} \mathrm{C}$ apresentou características como aparência e odor aceitáveis aos 20 dias, enquanto as amostras mantidas a $12^{\circ} \mathrm{C}$ apresentaram, em qualquer das embalagens, sinais visíveis de deterioração, com odores desagradáveis, manchas escuras e aparência limosa, a partir do quinto dia de estocagem. As amostras acondicionadas nas bandejas seladas com filme de PVC termoencolhivel apresentaram características de deterioração no $20^{\circ}$ dia de estocagem a $5^{\circ} \mathrm{C}$. Devido a evidentes alterações visuais, não foram realizadas as análises em 20 dias para amostra armazenada a $5^{\circ} \mathrm{C}$, nem as análises em 10, 15 e 20 dias a $12^{\circ} \mathrm{C}$.

\section{2 - Alterações no perfil gasoso e no pH do repo- lho minimamente processado durante conservação a diferentes temperaturas}

Nas embalagens de repolho minimamente processado, as concentrações iniciais de $\mathrm{CO}_{2}$ variaram em torno de $1,3 \%$ e as concentrações de $\mathrm{O}_{2}$ entre 9 e $12 \%$. As concentrações de $\mathrm{O}_{2}$ e de $\mathrm{CO}_{2}$ encontradas na amostra coletada, aproximadamente, 4 horas após o acondicionamento da hortaliça fatiada indicou que, nesse intervalo, ocorreu respiração intensa do vegetal, resultando em redução considerável de $\mathrm{O}_{2}$, e em elevação da concentração de $\mathrm{CO}_{2}$. Essa mudança relativamente rápida na composição gasosa dentro das embalagens pode ser atribuída ao aumento da taxa respiratória do tecido vegetal provocada pelo corte. Resultados apresentados por PRIEPKE, WEY \& NELSON [20] confirmam que o corte promove o aumento da taxa respiratória de hortaliças minimamente processadas. Diferença significativa $(\mathrm{P}<0,05)$ na composição gasosa entre as embalagens e no decorrer do tempo de estocagem a $1^{\circ} \mathrm{C}$ e $5^{\circ} \mathrm{C}$ foi verificada apenas para a concentração de $\mathrm{CO}_{2}$, apesar de os filmes avaliados apresentarem taxas diferentes de permeabilidade seletiva aos gases $\mathrm{CO}_{2}$ e $\mathrm{O}_{2}$.

As concentrações de $\mathrm{CO}_{2}$ nas embalagens PD900 e PD961 EZ foram, aproximadamente, iguais e, a partir do décimo dia, permaneceram numa faixa de 1,5\%. A concentração de $\mathrm{CO}_{2}$ nas embalagens de bandeja selada com filme de PVC termoencolhivel, estocadas a $1^{\circ} \mathrm{C}$ e $5^{\circ} \mathrm{C}$, foi sempre inferior a das outras duas embalagens avaliadas, e, a partir do décimo dia, permaneceu na faixa de $0,5 \%$ a $0,8 \%$. Embora as embalagens avaliadas apresentassem permeabilidade diferente ao $\mathrm{O}_{2}$, as concentrações desse gás, no interior das mesmas, mantidas a $1^{\circ} \mathrm{C}$ e $5^{\circ} \mathrm{C}$ por até 20 dias, não apresentaram variação significativa. É provável que o volume livre dentro das embalagens de $420 \mathrm{~mL}$, cerca de três vezes maior que o volume do repolho acondicionado $(150 \mathrm{~mL})$, tenha proporcionado um grande volume gasoso para trocas entre a atmosfera e o interior das embalagens, resultando na detecção de pequena variação da concentração de gases no interior das embalagens.

Os valores de $\mathrm{pH}$ das amostras de repolho minimamente processado aumentaram, significativamente, de um valor inicial de 5,6 para um valor médio de 6,5, após 20 dias de estocagem, não sendo detectadas diferenças nesses valores, nas amostras embaladas nos diferentes filmes plásticos e mantidas a $1^{\circ} \mathrm{C}$ e $5^{\circ} \mathrm{C}$. Os resultados encontrados no presente trabalho diferem daqueles reportados por LARSON et al. [14], que detec- 
taram decréscimo dos valores iniciais de $\mathrm{pH}$ durante estocagem de várias hortaliças, a $4^{\circ} \mathrm{C}, 12^{\circ} \mathrm{C}$, e $21^{\circ} \mathrm{C}$. Esses autores verificaram que, nas amostras de repolho minimamente processado, o $\mathrm{pH}$ inicial de 6,4 apresentou decréscimo para valores iguais ou inferiores a 4,6, após a deterioração, que ocorreu em dias diferentes, de acordo com a temperatura de estocagem.

\section{3 - Alterações na microbiota contaminante do repolho minimamente processado}

A contagem padrão inicial de microrganismos aeróbios mesófilos e de psicrotróficos, que foi de aproximadamente $10^{4} \mathrm{UFCg}^{-1}$, não variou durante 20 dias de estocagem a $1^{\circ} \mathrm{C}$ e $5^{\circ} \mathrm{C}$, nas amostras de repolho estocadas nas três embalagens avaliadas (Figuras 1 e 2). Diferenças nas populações de aeróbios mesófilos em repolho minimamente processado acondicionadas em embalagens com alta e baixa permeabilidade ao $\mathrm{O}_{2}$ também não foram observadas por HAO et al. [11]. No entanto, em outras hortaliças minimamente processadas, podese constatar aumentos de 2 a $3 \log _{10} \mathrm{UFCg}^{-1}$ mesmo no produto mantido a baixas temperaturas. A população de aeróbios mesófilos em alface minimamente processada variou de $10^{4}$ a $10^{7} \mathrm{UFCg}^{-1}$ durante estocagem a $4^{\circ} \mathrm{C}$ por 12 dias [3]. BABIC \& WATADA [2] observaram aumento nas populações de aeróbios mesófilos em folhas de espinafre minimamente processadas de valores iniciais de $10^{7}$ a $10^{8} \mathrm{UFCg}^{-1}$ para até $10^{10} \mathrm{UFCg}^{-1}$, durante estocagem em ar e atmosfera controlada, mantidas a $5^{\circ} \mathrm{C}$ por 9 dias.

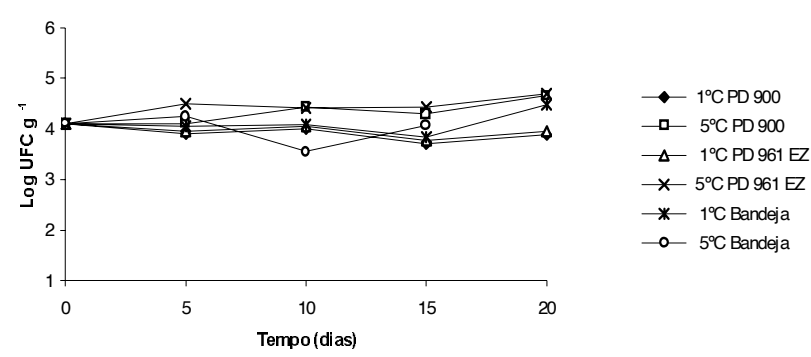

FIGURA 1. Contagem padrão de bactérias aeróbias mesófilas em repolho minimamente processado estocado a $1^{\circ} \mathrm{C}$ e $5^{\circ} \mathrm{C}$.

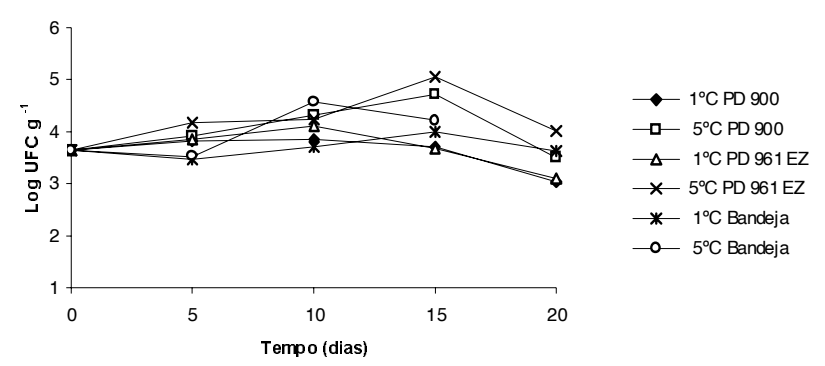

FIGURA 2. Contagem padrão de bactérias psicrotróficas em repolho minimamente processado estocado a $1^{\circ} \mathrm{C}$ e $5^{\circ} \mathrm{C}$.

Aumentos de cerca de $3 \log _{10} \mathrm{UFCg}^{-1}$ na população microbiana aeróbia mesófila e psicrotrófica do produto foram constatados nas embalagens mantidas em abuso de temperatura de $12^{\circ} \mathrm{C}$ após 5 dias (dados não apre- sentados). Nessas condições, não foram detectadas alterações acentuadas na composição da atmosfera no interior das embalagens, nem no $\mathrm{pH}$ das amostras de repolho. Resultados semelhantes foram apresentados por PIAGENTINNI et al. [19] que observaram aumentos da ordem de 2 a $3 \log _{10} \mathrm{UFCg}^{-1}$ no número de aeróbios mesófilos em repolho minimamente processado e estocado a $12^{\circ} \mathrm{C}$ e $20^{\circ} \mathrm{C}$, em relação ao produto estocado a $4^{\circ} \mathrm{C}$. LARSON et al. [14] detectaram um aumento de contaminantes de $10^{5}$ para $10^{8} \mathrm{UFCg}^{-1}$, após 3 dias de estocagem, a $12^{\circ} \mathrm{C}$, em amostras de repolho minimamente processadas.

No presente estudo, após 10 dias de estocagem a $12^{\circ} \mathrm{C}$, as amostras de repolho minimamente processadas apresentaram características visiveis de deterioração e não foram submetidas às análises microbiológicas. A temperatura é um fator que exerce efeitos pronunciados na vida-de-prateleira de vegetais minimamente processados e, em alface, aumento de $100 \%$ na vidaútil do produto pode ser constatado reduzindo-se a temperatura de $10^{\circ} \mathrm{C}$ para $2^{\circ} \mathrm{C}[4]$.

A microbiota anaeróbia mesófila no repolho minimamente processado foi inicialmente de $10^{3} \mathrm{UFCg}^{-1} \mathrm{e}$ apresentou comportamento semelhante ao observado para aeróbios mesófilos e psicrotróficos durante estocagem a 1 e $5^{\circ} \mathrm{C}$ (Figura 3 ).

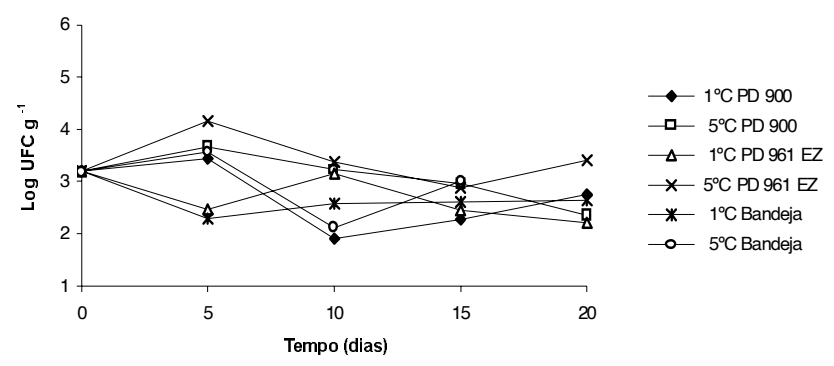

FIGURA 3. Contagem padrão de bactérias anaeróbias em repolho minimamente processado estocado a $1^{\circ} \mathrm{C}$ e $5^{\circ} \mathrm{C}$.

Mesmo não sendo verificada diferença na microbiota aeróbia e anaeróbia mesófila e de psicrotróficos no repolho minimamente processado estocado nas três embalagens avaliadas, foi possível perceber que, quando acondicionado em bandejas plásticas transparentes, seladas com filme de PVC termoencolhível, o produto apresentou no $20^{\circ}$ dia, a $5^{\circ} \mathrm{C}$, características sensoriais indesejáveis, o que não ocorreu nas outras embalagens estudadas. Estes resultados podem sugerir que o número dos microrganismos avaliados no produto não está diretamente relacionado com o período de vida-útil. É provável que outros fatores, como reações químicas e enzimáticas, bem como outra microbiota específica, como microrganismos pectinolíticos e fungos, devam estar associados com a deterioração do produto. De fato, ZAGORY [25] discute essa hipótese com base em dados disponiveis na literatura e considera que a extensão de vida-útil de frutas e hortaliças frescas parece ser independente dos efeitos dos microrganismos, pelo menos em alguns produtos. 


\section{4 - CONCLUSÕES}

A sanitização de repolhos inteiros com diferentes sanitizantes resultou na redução de até 1,8 ciclos logarítmicos na população de microrganismos aeróbios mesófilos. Os resultados das análises microbiológicas evidenciaram que o aumento da microbiota aeróbia e anaeróbia mesófila e psicrotrófica de repolho minimamente processado pode ser evitado em temperaturas de $5^{\circ} \mathrm{C}$ ou inferiores, resultando em aumento significante na vida-de-prateleira do produto. A temperatura de $12^{\circ} \mathrm{C}$, entretanto, permitiu aumento acentuado dessa microbiota, com resultante restrição da vida-de-prateleira para períodos inferiores a 5 dias.

\section{5 - REFERÊNCIAS BIBLIOGRÁFICAS}

[1] AHVENAINEM, R. New approaches in improving the shelf life of minimally processed fruit and vegetables. Trends in Food Science \& Technology, v. 7, p. 179-187, 1996.

[2] BABIC, I.; WATADA, A.E. Microbial populations of freshcut spinach leaves affected by controlled atmospheres. Postharvest Biology and Technology, v. 9, p. 187193, 1996.

[3] BARRIGA, M.I.; TRACHY, G.; WILLEMOT, C.; SIMARD, R.E. Microbial changes in shredded iceberg lettuce stored under controlled atmospheres. Journal of Food Science, v. 56, n. 6, p. 1586-1588, 1991.

[4] BOLIN, H.R.; STAFFORD, A.E.; KING JR., A.D.; HUXSOLL, C.C. Factors affecting the storage stability of shredded lettuce. Journal of Food Science, v. 42, n. 5, p. 1319-1321, 1977.

[5] BUICK, R.K.; DAMOGLOU, A.P. The effect of vacuum packaging on the microbial spoilage and shelf-life of 'ready-to-use' sliced carrots. Journal of the Science and Food Agriculture, v. 38, p. 167-175, 1987.

[6] COUSIN, M.A.; JAY, J.M.; VASADA, P.C. Psychrotrophic microorganisms. In: VANDERZANT, C.; SPLITTSTOESSER, D.F. (eds.) Compendium of Methods for the Microbiological Examination of Foods. 3. ed. S. L.: APHA - American Public Heatlh Association, 1992, p. 153-165.

[7] GARCÍA-GIMENO, R.M.; ZURERA-COSANO, G.; AMAROLÓPEZ, M. Incidence, survival and growth of Listeria monocytogenes in ready-to-use mixed vegetable salads in Spain. Journal of Food Safety, v. 16, p. 75-86, 1996.

[8] GARCÍA-GIMENO, R.M.; ZURERA-COSANO, G. Determination of ready-to-eat vegetable salad shelf-life. International Journal of Food Microbiology, v. 36, p. 31-38, 1997.

[9] GARCÍA-GIMENO, R.M.; SANCHEZ-POZO, M.D.; AMAROLÓPEZ, M.A.; ZURERA-COSANO, G. Behaviour of Aeromonas hydrophila in vegetables salads stored under modified atmosphere at 4 and $15^{\circ} \mathrm{C}$. Food Microbiology, v. 13, p. 369-374, 1996.

[10] GUERZONI, M.E.; GIANOTTI, A.; CORBO, M.R.; SINIGAGLIA, M. Shelf-life modeling for fresh-cut vegetables. Postharvest Biology and Technology, v. 9, p. 195-297, 1996.

[11] HAO, Y.Y.; BRACKET, R.E.; BEUCHAT, L.R.; DOYLE, M.P. microbiological quality and the inability of proteolytic Clostridium botulinum to produce toxin in film-packaged fresh-cut cabbage and lettuce. Journal of Food Protection, v. 61, n. 9, p. 1148-1153, 1998.
[12] JACXSENS, L.; DEVLIEGHERE, F.; DEBEVERE, J. Behavoir of Listeria monocytogenes and Aeromonas spp on fresh-cut produce packaged under equilibriummodified atmosphere. Journal of Food Protection, v. 62, p. 1128-1135, 1999.

[13] JACXSENS, L.; DEVLIEGHERE, F.; DEBEVERE, J. Predictive modelling for packaging design: equilibrium modified atmosphere packages of fresh-cut vegetables subjected to a simulated distribution chain. International Journal of Food Microbiology, v. 73, p. 331-341, 2002.

[14] LARSON, A.E.; JOHNSON, E.A.; BARMORE, C.R.; HUGHES, M.D. Evaluation of the botulism hazard from vegetables in modified atmosphere packaging. Journal of Food Protection, v. 60, n. 10, p. 1208-1214, 1997.

[15] MASIH, L.; ROGINSKI, H.; PREMIER, R.; TOMKINS, B.; AJLOUNI, S. Soluble protein content in minimally processed vegetables during storage. Food Research International, v. 35, p. 697-702, 2002.

[16] NGUYEN-THE, C.; CARLIN, F. The microbiology of minimally processed fresh fruits and vegetables. Critical Reviews in Food Science and Nutrition, v. 34, n. 4, p. 371-401, 1994.

[17] PARK, W.P.; LEE, D.S. Effect of chlorine treatment on cut water cress and onion. Journal of Food Quality, v. 18, p. $415-424,1995$.

[18] PETRAN, R.L.; SPERBER, W.H.; DAVIS, A.B. Clostridium botulinum toxin formation in romaine lettuce and shredded cabbage: efect of storage and packaging conditions. Journal of Food Protection, v. 58, p. 624-627, 1995.

[19] PIAGENTINNI, A.M.; PIROVANI, M.E.; GÜEMES, D.R.; DI PENTIMA, J.H.; TESSI, M.A. Survival and growth of Salmonella hadar on minimally processed cabbage as influenced by storage abuse conditions. Journal of Food Science, v. 62, n. 3, p. 616-618, 1997.

[20] PRIEPKE, P.E.; WEI, L.S.; NELSON, A.I. Refrigerated storage of prepackaged salad vegatables. Journal of Food Science, v. 41, p. 379-382, 1976.

[21] SHEWfELT, R.L. Postharvest treatment for extending the shelf life of fruits and vegetables. Food Technology, n. 5, p. 70-80, 1986.

[22] SWANSON, K.M.J.; BUSTA, F.F.; PETERSON, E.H.; JOHNSON, M.G. Colony Count Methods. In: VANDERZANT, C.; SPLITTSTOESSER, D.F. (eds) Compendium of Methods for the Microbiological Examination of Foods. 3 ed. APHA - American Public Heatlh Association, 1992, p. 75-95.

[23] WATADA, A.L.; QI, L. Quality of fresh-cut produce. Postharvest Biology and Technology, v. 15, p. 201205, 1999.

[24] WILEY, R. 1994. Minimally Processed Refrigerated Fruits \& Vegetables. Chapman \& Hall, New York. 368p.

[25] ZAGORY, D. Effects of post-processing handling and packaging on microbial populations. Postharvest Biology and Technology, v. 15, p. 313-321, 1999.

[26] ZHANG, S.; FARBER, J.M. The effects of various disinfectants against Listeria monocytogenes on fresh-cut vegetables. Food Microbiology, v. 13, p. 311-321, 1996.

\section{6 - AGRADECIMENTOS}

Ao PRODETAB - Projeto de Apoio ao Desenvolvimento de Tecnologia Agropecuária para o Brasil pelo apoio financeiro. 